\title{
Использование информационно-коммуникационных технологий в образовательных процессах южнокорейских университетов: опыт российских студентов
}

\author{
И.И. Толстикова ${ }^{1}$, А.А. Толстикова ${ }^{2}$ \\ ${ }^{1}$ Университет ИТМО, ${ }^{2}$ Санкт-Петербургский государственный университет \\ tolstikova_irina@mail.ru; tolstikova.anna@gmail.com
}

\section{Аннотация}

Данная статья предлагает рассмотреть опыт применения информационнокоммуникационных технологий в образовательных процессах и социальных практиках южнокорейских университетов. Рассматривается история внедрения информационно-коммуникационных технологий в развитии системы высшего образования в Республике Корея, исследуется система организации информационного пространства университетов.

Выделяются отличительные черты структуры единого информационного пространства, а также технологий дистанционного электронного обучения. Для обсуждения конкретных примеров использования ИКТ в южнокорейских вузах используется эмпирический материал, полученный в ходе социологического исследования опыта обучения в Корее российских студентов.

Ключевые слова: образовательная миграция, социальный сёрфинг, икт в образовательных процессах

Библиографическая ссылка: Толстикова И. И., Толстикова А. А. Использование информационно-коммуникационных технологий в образовательных процессах южнокорейских университетов: опыт российских студентов // Информационное общество: образование, наука, культура и технологии будущего. Выпуск 3 (Труды XXII Международной объединенной научной конференции «Интернет и современное общество», IMS-2019, Санкт-Петербург, 19 - 22 июня 2019 г. Сборник научных трудов). - СПб: Университет ИТМO, 2019. С. 141 - 148. DOI: 10.17586/2587-85572019-3-141-148

\section{Вступление}

На современном этапе развития Республики Корея является одной из самых высокодинамично развивающихся стран в сфере информационных технологий, что не могло не отразиться на важнейших сферах жизнедеятельности корейского общества. Одной из самых перспективных сфер, формирующих динамику государственной политики Республики Корея, является качественное развитие сферы высшего образования.

Высокое качество образования, регулируемое на государственном уровне, стало одной из главных причин экономического роста Республики Корея, внеся существенный вклад в развитие человеческого капитала, способного к поглощению передовых технологий и разработке собственных технологий как в количественном, так и в качественном отношении.

\section{1. Роль Правительства Республики Кореи}

Необходимо отметить особенность корейской системы высшего образования. История современного высшего образования в Корее еще достаточно коротка. В 2019 году 
исполнилось 134 года первому в стране частному университету Йонсей (Yonsei university), основанному группой американских миссионеров и врачей. Остальные корейские университеты еще моложе. Первый государственный вуз, Сеульский национальный университет (Seoul National University), появился только в 1946 году - 73 года назад. Он был трансформирован в классический университет путем слияния японского Имперского колледжа Гюнсун с другими двухгодичными профессиональными школами, находившимися в Сеуле. Несмотря на то, что высшее образование в течение нескольких веков вплоть до конца XIX века находилось под влиянием Китая, а затем в колониальный период 1910-1945 гг. испытало воздействие японской образовательной системы, современная корейская система высшего образования во многом повторяет североамериканскую. Это обусловлено тем, что основы корейского высшего образования заложило военное правительство армии США в конце Второй мировой войны (что совпадает с концом японского правления). США оказывали финансовую помощь, а также способствовали организации посещений американскими учеными корейских вузов с целью консультирования в области разработки учебных программ и общей институциональной системы [1, с.100].

История внедрения информационных технологий в образовательный процесс Республики Корея начинается в 1980-е гг. Первая попытка внедрить ИКТ в систему корейского образования был предложена в виде инициативы комитета образовательной инновации Министерства образования Республики Корея «План реновации образования $5.31 »$. Был разработан пятилетний план использования ИКТ в образовании. Проект был введен в 2010 году и сейчас находится на 4 этапе внедрения [2, p.3]. Высокий уровень внедрения и использования информационно-коммуникационных технологий в корейское общество зафиксирован в Индексе развития информационно-коммуникационных технологий в странах мира ICT Development Index, в соответствии с которым Республика Корея на протяжении нескольких лет занимала 1 и 2 второй место (в 2017 году -2 место) [3, c. 43].

Благодаря развитой инфраструктуре информационно-коммуникационных технологий и технологий электронного обучения, уровень информатизации в области высшего образования в Корее соответствует высокому международному уровню, а сам образовательный процесс и его результаты являются приоритетами государственной политики.

Корея является признанным мировым лидером в развитии электронного образования и благодаря огромным инвестициям реально осуществляет адаптацию всей системы образования к информационной эпохе. Методы e-learning в системе преподавания используются в $80 \%$ университетов Кореи [4, с.17].

Следует отметить упорное стремление корейцев к получению образования, роль правительства и создание соответствующей инфраструктуры, что стало благодатной почвой для внедрения Smart-образования в Корее. Студент в Корее - это член Smart-общества, который учится на протяжении всей своей жизни, пытается создать и создает инновации. Студент в Корее - это член Smart-общества, который учится на протяжении всей своей жизни, пытается создать и создает инновации. Большинство корейцев ценят знания превыше всего, и даже в возрасте восьмидесяти лет не боятся обучаться, а наоборот используют каждую возможность. В Южной Корее люди от тридцати до сорока составляют самое большое количество студентов в процентном соотношении, количество сорокалетних обучающихся не уступает двадцатилетним обучающимся, и почти $90 \%$ студентов в Южной Корее работает. На рынке e-learning в Южной Корее работает более 700 компанийпровайдеров электронного обучения, около 40 компаний, которые получают прибыль более 10 млн долл. США. Использование электронного обучения в Южной Корее регулируется следующими законодательными актами и стандартами: Закон о развитии профессионального образования и тренингов (1997); Закон о непрерывном образовании (1999); Закон об управлении знаниями и информационными ресурсами (2000); Закон об 
электронном правительстве (2001); Закон о развитии индустрии e-learning (2004); Закон о развитии в сфере использования цифрового онлайн контента (2006); Стандарт качества электронного обучения (2006); Закон об авторском праве: внесение поправок (2007); Акт о неразглашении образовательной информации (2007) [4, с.18].

Новым является внедрение и развитие системы открытого образования в Южной Корее. Необходимо отметить апробирование массовых открытых онлайн курсов, взятых из зарубежной практики. В 2015 году с одобрения Министерства образования Республики Корея была создана Национальная платформа корейских массовых открытых образовательных онлайн курсов Korean Massive Open Course (K-MOOC) ${ }^{1}$, в целях формирования которой ведущими корейскими университетами были заключены контракты c edX, Coursera и другими ведущими корпорациями для создания совместного контента. В проекте участвует более 70 ведущих университетов Кореи, в том числе Сеульский национальный университет, Корейский университет передовых технологий KAIST и др. Видео-лекции на иностранных языках размещаются с субтитрами на корейском языке.

Также созданы онлайн-платформы на базе отдельных университетов. В качестве примера можно привести Сеульский национальный университет, создавший платформу $\mathrm{SNUx}^{2}$ в 2014 году, на которой представлены онлайн курсы лекторов данного университета.

\section{2. Организация образовательного процесса глазами российских студентов}

В рамках социологического исследования на тему «Карьерные траектории выпускников южнокорейских университетов» проведено десять глубинных интервью с гражданами Российской Федерации, которые обучались в магистратуре южнокорейского вуза (мужчины - 4, женщины - 6). В соответствии с выборкой исследования были опрошены выпускники англоязычных программ и закончившие данное обучение до 2012 года. Шесть информантов получили высшее образование (бакалавриат или специалитет) в России по специальности «корееведение», три информанта - по одной из специальностей в сфере экономики, маркетинга и искусства. При этом в группу филологической специальности помимо студентов, изучающих восточные языки, также отнесены студенты, которые специализировались на экономике с изучением корейского языка как второго иностранного. В южнокорейском вузе информанты обучались на англоязычной магистерской программе факультета международных отношений.

В ходе проведения глубинных интервью получены некоторые данные о внедрении и использовании инновационных информационно-коммуникационных технологий в студенческую образовательную среду корейских университетов. Сравнивая обучение в России и Корее, информанты подтверждали разный уровень внедрения технологий в образовательные процессы. Отличия охватывают как использование информационных технологий на инфраструктурном уровне - от записи на занятия в начале семестра до получения различных справок об обучении в корейском университете, так непосредственно в образовательном процессе - от обязательного использования мультимедийных презентаций до онлайн модулей в программе курса (e-learning).

\section{3. Инфраструктура в корейских университетах}

Информанты рассказали об организации информационного пространства университетов, современных формах организации учебного процесса и структуре информационных систем университетов. В университетских библиотеках наличествуют компьютерные залы для самостоятельной работы, в них можно зарезервировать время

\footnotetext{
${ }^{1} \mathrm{http}: / / \mathrm{www} \cdot \mathrm{kmooc} . \mathrm{kr} /$

${ }^{2} \mathrm{https}$ //www.edx.org/school/snux
} 
работы на конкретном компьютере заранее. Студенты имеют дистанционный доступ ко всем образовательным ресурсам, а также бесплатный скоростной безлимитный доступ в интернет. Для идентификации студента на территории университетов и доступа к различным ресурсам используется единая идентификационная карта студента со штрихкодом, которая функционирует и как банковская карта, и как читательский билет в библиотеке, и как пропуск в помещения с ограниченным доступом, и как средство оплаты, в том числе в автоматах по приему платежей и в автобусах.

В отличие от российских вузов, корейские университеты обычно располагаются локально на территории одного или двух кампусов, поэтому разработаны специальные рейсовые автобусные маршруты, которые подвозят студентов от ключевых образовательных корпусов к различным станциям метро или крупным автобусным терминалам. Некоторые университеты создали специальные приложения для внутреннего пользования, показывающие время прибытия того или иного автобуса.

В настоящее время в университете Йонсей действует программа Smart Campus, которая работает в соответствии с университетской концепцией OCX Open Campus Experience. Программа создана для получения любой информации о ресурсах и возможностях, существующих на территории кампуса. Через это приложение студенты оповещаются о различных культурно-развлекательных, образовательных и других мероприятиях, более того, разработан онлайн доступ к наблюдению за различными мероприятиями на территории университета. Преподаватели также могут закачивать видеозаписи, снятые во время лекций, или вести онлайн-трансляцию занятия для зарегистрированных учащихся на данный курс. С помощью данного приложения студенты и сотрудники университета также могут отслеживать движение рейсового автобуса до метро. Отмечается, что через данное приложение можно также отмечать посещаемость лекции, загружать курсовые работы на английском и корейском языках для проверки на анти-плагиат.

Другой отличительный момент - это отсутствие зачетных книжек у учащихся в корейском вузе. Безусловно, у студентов есть студенческий билет с функционалом, описанным выше, но оценки выставляются в личном кабинете каждого студента, таким образом, что невозможно посмотреть результаты других учащихся. В случае необходимости получения различных справок о зачислении в университет или о прослушанных предметах и оценках по ним, студенты имеют возможность самостоятельно обратиться к установленным в холле административного корпуса автоматам для распечатки тех или иных справок, уплатив при этом необходимую сумму, которая сравнима по стоимости с проездом в метро или автобусе.

\section{4. Возможность выбора предметов}

Что касается учебного плана в корейском вузе, то, во-первых, они строго не регламентированы, и студенты самостоятельно выбирают те предметы, которые они считают необходимыми для изучения. Так, например, можно выбрать от двух до шести предметов за семестр, два из которых должны быть обязательно профильными. Такая система самостоятельного формирования учебного процесса немного удивляла информантов, после четырех-пяти лет готовых расписаний в России им предлагали выбрать те дисциплины, которые они действительно хотели бы изучать. Данный подход к формированию индивидуального учебного плана мотивирует студентов к осознанному выбору предметов, обостряет чувство ответственности, вызывает интерес к занятиям по самостоятельно выбранным дисциплинам.

Регистрация на желаемые курсы осуществляется через личный кабинет в строго регламентированный временной промежуток, который делится на три этапа. Первый этап запись на предметы (2-3 дня); второй этап - подтверждение заявки (5-7 дней); третий этап - снятие участия в курсе (4 дня). Поскольку количество слушателей курсов ограничено, необходимо успеть зарегистрироваться на наиболее популярные предметы в первые часы 
(или даже минуты) открытия регистрации на занятия в новом семестре. Подтверждение участия приходит не моментально, а в строго выделенный для этого период, поэтому рекомендуется подавать сразу на несколько курсов сверх нормы на тот случай, если окажется, что студент не успел вовремя зарегистрироваться на курс и ему не хватило места в списке слушателей курса (с обязательным ограничением количества слушателей). При этом автоматически формируется «лист ожидания» для создания дополнительных возможностей на этапе корректировки списков. Для снятия своей кандидатуры на занятия «запасного варианта», предназначен третий этап регистрации на курсы. В этот период появляется шанс у студентов из листа ожидания.

Информанты также отмечали, что между университетами действует балльная система взаимозачета, позволяющая студентам записываться на курсы, читаемые в других университетах. Запись осуществляется через тот же самый личный кабинет, не требуя дополнительных заявлений и ходатайств. Оценка за прослушанный предмет автоматически отражается после окончания сессии.

В процессе обучения студент вступает в череду ситуаций социального самоопределения. Выбирая те или иные предметы на предстоящий семестр, ориентируясь на легкость освоения, интерес к предмету или его пользу для будущей профессии, студент формирует социальную колею, которая задает направление развития его потенциально возможной карьерной траектории [6, с. 34-35]. Выработанные и принятые в национальной культуре Кореи морально-этические принципы порождают особую модель социального серфинга, которая, как особая коммуникативная тактика, сохраняет положительные социальные черты и не характеризуется ценностно-поведенческой лабильностью и снижением устойчивости социокультурных ориентаций, в отличие от европейской модели социального серфинга, имеющей достаточное количество отрицательных социальных черт [5, с.46].

\section{5. ИКТ и проведение занятий}

Информанты, которые учились в российских вузах в период с 2005 по 2008 гг., отмечали удивление тем, что большинство лекционных и реже семинарских занятий в корейском вузе сопровождались презентацией в формате Power Point. Bce аудитории оснащены компьютерами и мультимедийными проектами, учебные столы часто имеют розетки для ноутбуков.

Применялась практика дробления лекционного курса на аудиторных занятия и лекции и практические занятия онлайн, персонализированного обучения и «перевернутых» классов (Flipped Classrooms), игровые образовательные технологии. Модуль занятий в интернете предполагал создание идентификационного личного кабинета, который позволял преподавателю отслеживать прохождение студентов модулей и проверки ответов на практические задания. Модули можно проходить в любое удобное время, но строго в срок до официального окончания курса. В период сессии студенты получали доступ к онлайнтестированию с персонального компьютера в течение одного дня. Отмечается, что тест был построен таким образом, что время ответа на каждый вопрос был строго ограничен так, что поиск подсказки правильного ответа в интернете был невозможен.

\section{6. Содействие в трудоустройстве}

Корейские университеты, так же как и российские вузы, оказывают повсеместное содействие в реализации профессионального потенциала учащихся. В корейских учебных заведениях, к примеру, на факультетах международных отношений созданы собственные центры развития карьеры и трудоустройства, на страничках которых практически ежедневно публикуется информация о наборе на программы стажировок в компаниях, исследовательских центрах, представительствах ООН. Потенциальные работодатели, заинтересованные в выпускниках лучших университетов, заключают соглашения с этими 
вузами о наборе старшекурсников на учебную практику в компании, по результатам которой возможно поступление на службу в компанию. А получение работы в престижной компании сразу после окончания университета является очень важным для корейского выпускника. Работа не по специальности для выпускника корейского вуза является скорее исключением, чем правилом. Информация о стажировках и вакансиях часто размещается в разделе центрах развития карьеры, доступ к которым ограничен и предназначен для обучающихся данного факультета (рис. 1).

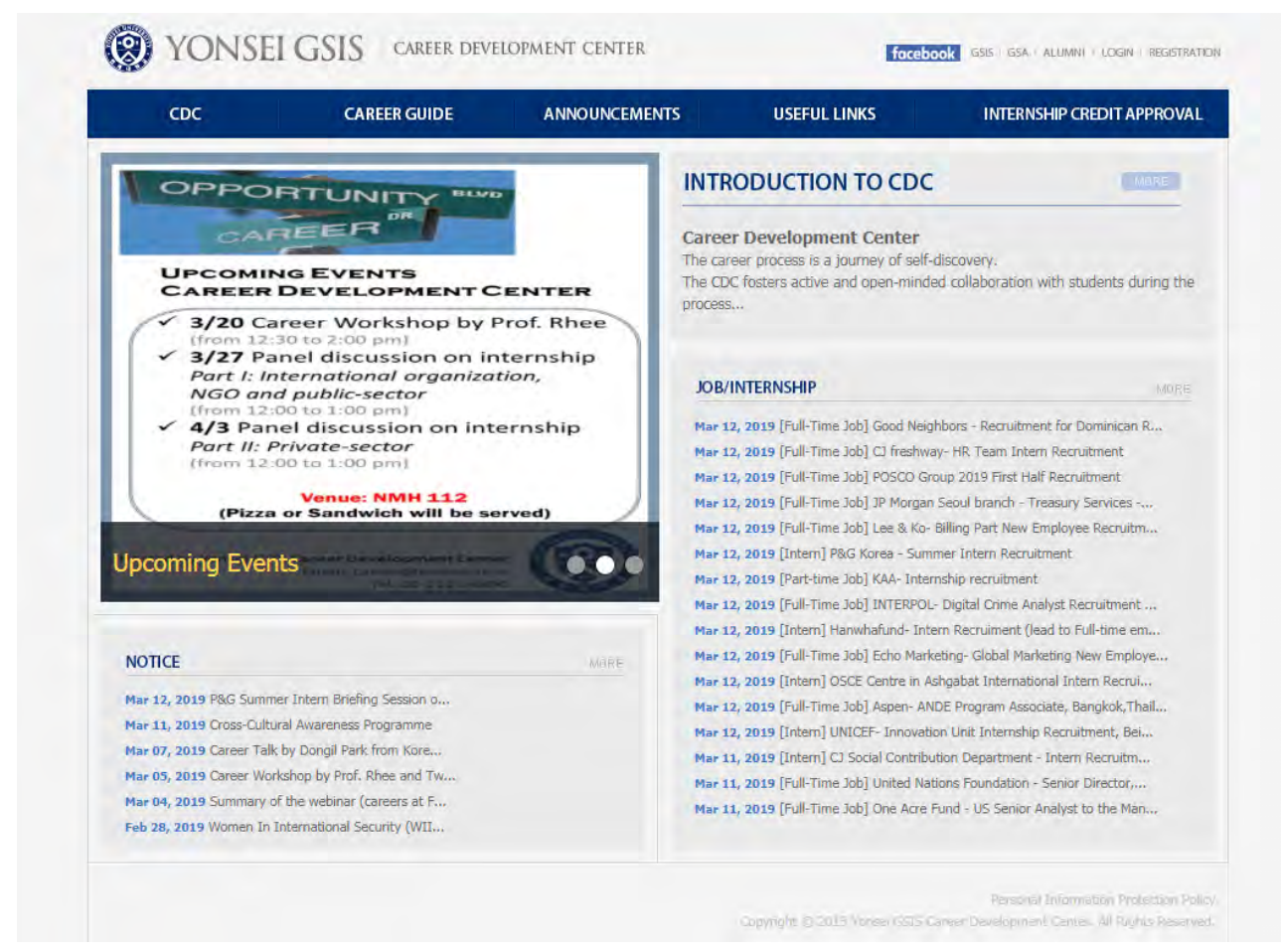

Рис. 1. Веб-страница Центра развития карьеры факультета международных отношений университета Йонсей с информацией о вакансиях и наборе на летние стажировки

Необходимо отметить, что в корейских корпорациях, таких как Samsung, LG и других компаниях-чеболях, два раза в год проводится программа набора молодых специалистоввыпускников вузов. Разработана целая система прохождения испытательных этапов для молодых кандидатов в удаленном доступе - конкурсный отбор резюме и мотивационных писем, тестирование вне зависимости от специализации кандидатов, ряд собеседований. По результатам отбора кандидату предлагают начать карьеру с должности младшего менеджера в департаменте, который наилучшим образом подходит, по мнению конкурсной комиссии.

Интересно, что выработанная в Корее система массового набора молодых специалистов порождает особую модель социальной колеи, которая предполагает поступление выпускника престижного университета на службу в компанию, при этом ограничивается его выбор направления и сферы деятельности. Период окончания университета является определенным жизненным перекрестком, когда в зависимости от социальной активности и быстроты реакции на информацию о рекрутинговых кампаниях, формируется индивидуальная профессиональная траектория [4, с.36]. 


\section{Заключение}

Семьдесят четыре года назад, с первых дней независимости, началась новая история этой страны, ориентированная на экспортно-ориентированную экономику. С девяностых годов двадцатого века был взят курс на построение информационного общества и одним из главных приоритетов развития стало образование. Чтобы стимулировать развитие научнообразовательного пула, в Республике Корея были предприняты значительные усилия по привлечению как государственных, так и частных инвестиций для внедрения новых цифровых технологий в сфере образования и создания условий для стимулирования развития интернет-услуг в образовании. Развитие образования через развитие цифровых технологий и инноваций, определение раннего образовательного маршрута, индивидуальные образовательные траектории - эти важные направления образовательной политики Республики Корея во многом определили повышение качества корейского образования, удовлетворенность и востребованность выпускников на рынке труда. Преодоление социальной инерции и применение логики социального серфинга в сфере образования приводит к эффекту возрастающей экономики, улучшению качества жизни, удовлетворенности полученным образованием.

Результаты внедрения инфокоммуникационных технологий в образовательный процесс и социальные практики университетов Кореи могут быть использованы в российской высшей школе, так как основные тенденции образования достаточно схожи.

Статья подготовлена при поддержке Российского фонда фундаментальных исследований, грант № №17-33-00063 («Механизмы воспроизводства и флексибилизации индивидуальной жизненной колеи: российская молодежь в контексте «жесткой» и «текучей» современности»).

\section{Литература}

[1] Дорога к академическому совершенству: Становление исследовательских университетов мирового класса / под ред. Ф. Дж. Альтбаха, Д. Салми; пер. с англ. - М.: Издательство «Весь Мир», 2012 - 416 с.

[2] Maciej Grzybowski. Educational Technologies in South Korea // General and Professional Education. 2013. № 1. P. 3-9. URL: http://genproedu.com/paper/2013-01.

[3] Баранов А.В., Тагаев А.В., Котлярова О.В. Система открытого образования в Республике Корея: перспективы внедрения // Среднерусский вестник общественных наук. 2017. №6. URL: https://cyberleninka.ru/article/n/sistema-otkrytogo-obrazovaniya-vrespublike-koreya-perspektivy-vnedreniya (дата обращения: 11.03.2019).

[4] Дондукова Н.Н. Электронное образование (e-leaming) в Республике Корея // Вестник БГУ. 2014. №15. URL: https://cyberleninka.ru/article/n/elektronnoe-obrazovanie-e-leamingv-respublike-koreya (дата обращения: 11.03.2019).

[5] Воробьва И.Ю., Кружкова О.Ю., Симонова И.А. Социальный серфинг: специфика ценностных ориентаций молодежи в современном обществе // Педагогическое образование в России. 2015. №5. C. 45-50. URL: https://cyberleninka.ru/article/v/sotsialnyy-serfing-spetsifika-tsennostnyh-orientatsiymolodezhi-v-sovremennom-obschestve.

[6] Ильин В.И. Социальный серфинг как модель молодежного образа жизни// Мониторинг общественного мнения: Экономические и социальные перемены. 2019. № 1. С. 28-48. DOI: 10.14515/monitoring.2019.1.02. 


\title{
ICT Usage in Educational Process of South Korean Universities
}

\author{
I. Tolstikova ${ }^{1}$, A. Tolstikova ${ }^{2}$ \\ ${ }^{1}$ ITMO University, ${ }^{2}$ St. Petersburg State University \\ tolstikova_irina@mail.ru; tolstikova.anna@gmail.com
}

The article covers the efforts to utilize Information and Communications Technology (ICT) in the Korean educational system and students' everyday life. There is a brief history overview of high education in Korea. To show the case of ICT usage in Korean universities we use the preliminary results of sociological survey on the Russia's students experience in Korean universities.

Keywords: educational migration, social surfing, ICT in educational process

Reference for citation: Tolstikova I., Tolstikova A. Technogenic Ideals and Humanitarian Values in a Digital Society // Information Society: Education, Science, Culture and Technologies of the Future. Vol. 3 (Proceedings of the XXII International Joint Scientific Conference «Internet and Modern Society», IMS-2019, St. Petersburg, June 19-22, 2019). - St. Petersburg: ITMO University, 2019. P. 141 - 148. DOI: 10.17586/2587-8557-2019-3-141-148

\section{Reference}

[1] Doroga k akademicheskomu sovershenstvu: Stanovleniye issledovatelskikh universitetov mirovogo klassa / pod red. F. Dzh. Altbakha, D. Salmi; per. s angl. - M.: Izdatelstvo «Ves Mir», $2012-416$ p.

[2] Maciej Grzybowski. Educational Technologies in South Korea // General and Professional Education. 1/2013. P.3-9. URL: http://genproedu.com/paper/2013-01.

[3] Baranov A.V., Tagayev A.V., Kotlyarova O.V. Sistema otkrytogo obrazovaniya v Respublike Koreya: perspektivy vnedreniya // Srednerussky vestnik obshchestvennykh nauk. 2017. №6. URL: https://cyberleninka.ru/article/n/sistema-otkrytogo-obrazovaniya-v-respublike-koreyaperspektivy-vnedreniya (data obrashcheniya: 11.03.2019).

[4] Dondukova N.N. Elektronnoye obrazovaniye (e-leaming) v Respublike Koreya // Vestnik BGU. 2014. №15. URL: https://cyberleninka.ru/article/n/elektronnoe-obrazovanie-e-leamingV-respublike-koreya (data obrashcheniya: 11.03.2019).

[5] Vorob'va I.Yu., Kruzhkova O.Yu., Simonova I.A. Social'nyj serfing: specifika cennostnyh orientacij molodezhi $\mathrm{v}$ sovremennom obshchestve//Psihologo-pedagogicheskie problemy obrazovaniya. P.45-50. URL: https://cyberleninka.ru/article/v/sotsialnyy-serfing-spetsifikatsennostnyh-orientatsiy-molodezhi-v-sovremennom-obschestve.

[6] Il'in V.I. Social'nyj serfing kak model' molodezhnogo obraza zhizni// Monitoring obshchestvennogo mneniya: Ekonomicheskie i social'nye peremeny. 2019. № 1. P. 28-48. https://doi.org/10.14515/monitoring.2019.1.02. 